\title{
Italie : les réformes éducatives au gré des alternances politiques (1999-2008)
}

Roger-François Gauthier et Teresa Longo

\section{OpenEdition}

12 Journals

Édition électronique

URL : http://journals.openedition.org/ries/390

DOI : 10.4000/ries.390

ISSN : 2261-4265

Éditeur

Centre international d'études pédagogiques

\section{Édition imprimée}

Date de publication : 1 septembre 2008

Pagination : 16-19

ISBN : 978-2-85420-573-2

ISSN : $1254-4590$

\section{Référence électronique}

Roger-François Gauthier et Teresa Longo, «Italie : les réformes éducatives au gré des alternances politiques (1999-2008) », Revue internationale d'éducation de Sèvres [En ligne], 48 | septembre 2008, mis en ligne le 27 juin 2011, consulté le 26 avril 2021. URL : http://journals.openedition.org/ries/390 ; DOI : https://doi.org/10.4000/ries.390

Ce document a été généré automatiquement le 26 avril 2021.

(c) Tous droits réservés 


\title{
Italie : les réformes éducatives au gré des alternances politiques (1999-2008)
}

\author{
Roger-François Gauthier et Teresa Longo
}

1 Depuis 1999, l'une des grandes questions de politique éducative en Italie est la réforme de la structure et des programmes de l'« école obligatoire $»^{1}$, objet fragile qui rebondit d'un ministre à l'autre à la grande vitesse des changements de gouvernements qui caractérise l'Italie depuis l'après-guerre.

\section{Centre-gauche : développer la scolarisation...}

2 En 1999, un gouvernement de centre gauche, conscient du retard de l'Italie par rapport au reste de l'Europe en la matière, décida d'augmenter de deux ans la durée de l'école obligatoire: alors que les jeunes sortaient jusque là de l'école obligatoire à l'âge de quatorze ans, après huit années d'études (cinq années de primaire et trois années d'école moyenne "pour tous", la scuola media unificata), la réforme de l'obligation scolaire et des cycles instaura le schéma $7+5$, les sept premières années s'appelant "école de base ", les cinq autres (dont deux obligatoires) constituant le «secondaire supérieur ». Cela devait signifier la suppression de l'école moyenne et son intégration à l'école de base, ainsi que le changement des programmes du secondaire supérieur ainsi redéfini : simplement, comme cette réforme n'eut qu'un an pour elle, il ne se passa rien.

\section{Droite : choix des familles, autonomie des établissements, examens « maison »...}

En 2001, le gouvernement Berlusconi désigna $\mathrm{M}^{\mathrm{me}}$ Moratti comme ministre... de l'Instruction, qui n'était plus qualifiée de "publique ». La réforme précédente fut bloquée et une autre mise en place $^{2}$, dont la décision emblématique fut la suppression 
de la notion d'obligation scolaire, et son remplacement par un "droit à l'instruction » pour une période de douze ans (en commençant un an plus tôt, l'âge d'entrée en maternelle étant abaissé), mais dans un parcours qui n'est pas nécessairement le même pour tous. En effet, les jeunes en difficulté et qui le souhaitaient pouvaient choisir, après l'école de base, des études générales, professionnelles ou en alternance. Les autres idées-forces étaient le renforcement de l'autonomie des établissements, déjà en application depuis 1997, ainsi que des pouvoirs des régions.

4 Il ne fut pas facile à l'opposition parlementaire de gauche dans ce contexte, même si elle dénonça les risques encourus par l'école publique, de faire comprendre à l'opinion publique en quoi sa propre politique avait différé de celle du gouvernement Berlusconi : en effet, des thèmes comme la « dérégulation » du système éducatif par la fin du fonctionnariat des enseignants, l'autonomie des établissements, le libre choix de l'école par les parents, le renforcement du pouvoir du chef d'établissement, ou la flexibilité des curricula avaient été ceux de la gauche. Il est vrai que celle-ci avait toujours envisagé ses réformes dans la perspective d'un service conçu comme à la fois public et national.

5 Sur la scène politique, toutefois, un autre thème relatif à l'école opposa à ce moment-là les deux plus importants regroupements politiques italiens: la laïcité des contenus d'instruction et l'école privée. En effet, au cours des dernières années du gouvernement de Berlusconi, l'influence des conservateurs catholiques s'étendit à la question des programmes de sciences naturelles et l'opposition laïque dut se faire entendre fortement pour défendre l'enseignement des thèses de Darwin qui se trouvaient contestées. En outre, au même moment, plusieurs dispositions en faveur de l'autonomie des établissements allégèrent les contrôles sur les écoles privées, qui bénéficièrent par exemple du fait que les examens furent dès lors organisés avec les seules ressources internes des établissements, sans participation externe aux commissions d'examen.

\section{Retour du centre-gauche : le thème du contrôle national de la qualité de l'école}

6 Quand, en 2006, les partis de centre gauche revinrent au pouvoir, la première préoccupation du nouveau ministre Fioroni fut de s'attaquer à tout ce qui, sous le gouvernement précédent, relevait, selon les nouveaux gouvernants, d'une sorte de légèreté, par exemple en « laissant faire » les établissements.

7 Ainsi, des évaluateurs extérieurs aux établissements furent réintroduits dans les commissions d'examens de fin d'études secondaires (maturità). Dans le même sens d'une attention apportée au sérieux des études ainsi qu'au caractère national des références scolaires, l'examen de fin d'école moyenne devint national. De même encore, une loi de 2007 réintégra dans le système éducatif national les établissements techniques et professionnels qui avaient été transférés à l'administration régionale par le gouvernement précédent. Sur la question des «dettes » des élèves, c'est-à-dire la possibilité qu'a un élève de ne pas redoubler, mais de passer dans la classe supérieure tout en ayant l'obligation ultérieure de combler des lacunes, appelées "dettes", le gouvernement de gauche voulut limiter l'impact négatif de leur accumulation sur le cursus des élèves, en leur faisant obligation de solder leurs dettes de l'année $n$ avant la fin de l'année $n+1$. Enfin un système d'évaluation fut mis en place, avec l'INVALSI 
(Istituto nazionale per la valutazione del sistema educativo di istruzione e di formazione), chargé des évaluations périodiques des acquis des élèves et de la qualité de l'offre de formation des établissements scolaires : cet institut fut créé sous l'autorité du ministre, avec une autonomie technique, mais il rencontra l'opposition des structures bureaucratiques préexistantes et des syndicats d'enseignants.

8 Une autre action du ministre Fioroni, en réaction à ses prédécesseurs, fut aussi de réinstaurer la scolarisation sur toute la journée, au niveau de l'école obligatoire (certains catholiques y voient une menace pour l'éducation familiale et religieuse).

9 Sur le thème des enfants des immigrés sans permis de séjour, le ministre dut faire face à certaines régions et municipalités gouvernées par l'opposition qui refusèrent d'accueillir ces enfants : au nom du respect des droits de l'enfant et des engagements internationaux de l'Italie, Fioroni parvint à imposer l'admission de ces élèves dans les établissements de Milan.

10 Sur la question de l'obligation scolaire, le gouvernement de centre gauche reprit le concept et la loi réaffirma l'idée d'obligation scolaire, en en fixant la durée à dix ans, l'âge d'accès au travail étant relevé à seize ans ${ }^{3}$. Le curriculum est national. En outre est prévue la possibilité de créer des parcours de formation, par convention entre le ministère et les régions, mais dans le cadre national. Le curriculum prévoit aussi que les établissements gèrent d'une façon autonome $20 \%$ de leur temps.

\section{Législatives de 2008 : vers plus d'autonomie financière et managériale}

11 "Nous pouvons reprendre le travail après deux années d'interruption ": ainsi s'exprima S. Berlusconi à son retour comme Président du Conseil après les élections de mai 2008, ce qui signifie pour l'école une nouvelle période d'incertitude. Pendant la campagne électorale, le parti vainqueur a promis à ses électeurs une école plus dynamique et plus moderne, l'autonomie régionale et celle des établissements, éléments considérés comme prioritaires, avec en particulier une autonomie financière accrue et le droit pour le proviseur de recruter les enseignants. 


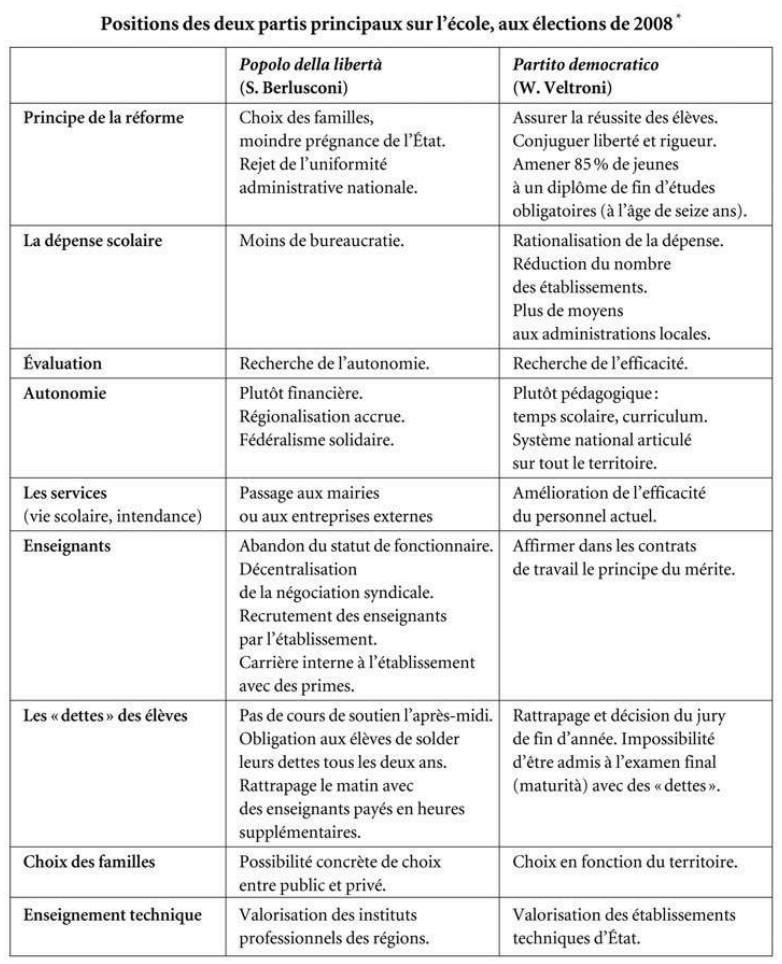

* Les questions scolaires n'y ont pas été centrales.

12 Si l'alternance politique à période brève est rarement favorable aux politiques éducatives, on peut se demander si le pendule italien va continuer d'osciller largement, quitte à ce qu'aucune réforme ne soit menée à bien, ou si, autour de quelques idées comme l'évaluation, se trouvera peu à peu un point d'équilibre. Encore faudra-t-il voir si ce point d'équilibre s'atteint au plan national ou dans la diversité scolaire des régions que les résultats de PISA ont soulignée.

\section{NOTES}

1. Scuola dell'obbligo : concept de référence qui désignait traditionnellement l'ensemble "école primaire et école moyenne ».

2. Une loi de 2001 recréa la scuola media dans un système reprenant le schéma 5+3.

3. Il n'y a que dans des cas exceptionnels et contrôlés par le ministère qu'il est possible de remplir l'obligation scolaire dans des établissements de formation professionnelle. 
INDEX

Mots-clés : politique éducative, réforme de l'enseignement, système éducatif Index géographique : Italie

\section{AUTEURS}

\section{ROGER-FRANÇOIS GAUTHIER}

Inspecteur général de l'administration de l'Éducation nationale et de la recherche, France.

\section{TERESA LONGO}

Maître de conférences, Université de Picardie Jules Verne d'Amiens, France. 